\title{
Morbidities and medications used by practicing nurses during the climacteric
}

\author{
Maria Cristina Tani Beneventi* (1), Sônia Maria Rolim Rosa Lima²
}

\section{SUMMARY}

OBJECTIVE: This study aimed to identify the morbidities and medications used by nurses practicing in São Paulo, Brazil, during the climacteric period to raise awareness and contribute to future preventive health measures in this population.

METHODS: A descriptive, cross-sectional study of 218 nurses aged 46-65 years based on data collected between January 2018 and July 2019 using a self-administered questionnaire was conducted.

RESULTS: Respondents had a mean age of $53.9 \pm 5.1$ years, mean weight of $71.3 \pm 13.6 \mathrm{~kg}$, mean waist circumference of $91.6 \pm 14.5 \mathrm{~cm}$, and mean body mass index of $27.8 \pm 4.9 \mathrm{~kg} / \mathrm{m}^{2}$. Notably, $70.5 \%$ did not menstruate, had a mean age at last menstruation of $47.5 \pm 6.2$ years and mean total score (Menopause Rating Scale) of 10.8 \pm 8.1 , and reported the following morbidities: dyslipidemia (35.5\%), subarachnoid hemorrhage (31.0\%), rheumatologic diseases (14.8\%), coronary heart disease (10.3\%), diabetes (10.2\%), malignant tumors (5.5\%), deep venous thrombosis (3.2\%), stroke (2.8\%), and pulmonary embolism (0.5\%). Medications used are antihypertensive agents (28.7\%), antidyslipidemic agents (20.6\%), antidiabetic agents (10.2\%), antidepressants (9.6\%), and anxiolytic agents (8.9\%).

CONCLUSIONS: The most prevalent climacteric symptoms were somatic and psychological, most notably physical and mental exhaustion and muscle and joint issues. The most common morbidities were anxiety, dyslipidemia, arterial hypertension, depression, arthrosis, arthritis and rheumatologic diseases, osteoporosis, diabetes mellitus, and coronary heart disease. The most frequently used medications were antihypertensive agents, antidyslipidemic agents (statins), antidiabetic agents, antidepressants, and calcium supplements. The study results furnish information on the health of practicing nurses during the climacteric period to inform preventive measures aimed at the main risk factors for morbidities to which nurses are exposed during this period.

KEYWORDS: Climacteric. Menopause. Morbidity. Pharmaceutical preparations. Nurses. Nursing.

\section{INTRODUCTION}

The climacteric period marks the transition from the reproductive to nonreproductive phase and, although physiological, manifests differently for each woman ${ }^{1,2}$.

Menopause is a point within the climacteric, diagnosed following 12 consecutive months of amenorrhea and sera levels of follicle-stimulating hormone (FSH) $\geq 25 \mathrm{UI} / \mathrm{mL}$, after ruling out pathological causes. Statistically speaking, menopause occurs, on average, at 50 years, whereas the climacteric begins at around 40 and extends up to 65 years of age ${ }^{3,4}$.

Another issue to consider is the metabolic risk factors comprising the metabolic syndrome (MetS), which are precursors of cardiovascular diseases (CVDs), given that the prevalence of MetS rises between premenopausal and postmenopausal periods. MetS is a complex disorder characterized by a group of cardiovascular risk factors usually associated with the central

\footnotetext{
'Santa Casa de São Paulo, Faculdade de Ciências Médicas - São Paulo (SP), Brazil.

${ }^{2}$ Santa Casa de São Paulo, Faculdade de Ciências Médicas, Departamento de Obstetrícia e Ginecologia - São Paulo (SP), Brazil.

*Corresponding author: mctbeneventi@gmail.com

Conflicts of interest: the authors declare there is no conflicts of interest. Funding: this study was funded by the Coordenação de Aperfeiçoamento de Pessoal de Nível Superior - Brazil (CAPES).

Received on August 20, 2021. Accepted on August 20, 2021.
} 
deposition of fat and insulin resistance. The association of MetS with CVD is important, increasing general mortality 1.5 -fold and cardiovascular mortality 2.5 -fold ${ }^{5-7}$.

CVD is the leading cause of death worldwide. In Brazil, this pattern is no different, and despite a declining trend, the disease still accounts for $34.2 \%$ of deaths. Women develop the disease later than men, with a typical lag of 10 years. This marked increase in CVD is seen after menopause, supporting the hypothesis that the steady decline in hormone production during the menopausal transition period increases cardiovascular risk ${ }^{6}$.

The nursing profession in Brazil is regulated by Law $\mathrm{n}^{\circ}$ 7.498, of June 25, 1986, and Decree $\mathrm{n}^{\circ}$ 94.406, of June 8 , $1987^{8}$. Nursing is the profession with the second largest number of professionals, over 2.2 million, comprising predominantly women. In São Paulo state, there are 506,846 registered nursing professionals overall, of which 134,518 are nurses and $86.47 \%$ women'.

Therefore, the objective of this study was to identify the morbidities and medications used by nurses practicing in São Paulo, Brazil, during the climacteric. The results can raise awareness of and contribute to the adoption of educational and preventive measures targeting the main risk factors of morbidities to which nurses are exposed during this period.

\section{METHODS}

A cross-sectional study involving a descriptive analysis of 218 nurses aged 46-65 years practicing at public and private health institutions in São Paulo, Brazil, was conducted.

\section{Ethical aspects}

This study was approved by the Research Ethics Committee of the Irmandade da Santa Casa de Misericórdia de São Paulo, under permit $n^{\circ} 3.728 .222 / 2019$. The following institutions were co-participants in this study: Conjunto Hospitalar do Mandaqui (CHM), permit no 3.782.883/2019; Hospital do Servidor Público Municipal (HSPM), permit $n^{\circ}$ 3.787.697/2019; and Hospital das Clínicas da Faculdade de Medicina da Universidade de São Paulo (HCFMUSP), Permit $\mathrm{n}^{\circ}$ 3.803.718/2019. Data collection was also approved at the facilities of the São Paulo Headquarters of the Regional Board of Nursing (Coren-SP), Administrative Process $n^{\circ}$ 2882/2017.

The objectives of this study were explained to all participating nurses both verbally and via an explanatory leaflet. All participants signed the free and informed consent form, in accordance with Resolution $n^{\circ}$. 466/2012 of the National Board of Health ${ }^{10}$.

\section{Data collection}

A self-report questionnaire was devised collecting data on sociodemographics, professional qualifications, lifestyle habits, and general aspects of health. Symptoms specific to the climacteric were investigated using the Menopause Rating Scale (MRS) incorporated in the questionnaire under the following inclusion and exclusion criteria:

\section{Inclusion criteria}

Nurses aged 46-65 years, practicing in the health services.

\section{Exclusion criteria}

Nurses not practicing in health services.

\section{Statistical methods}

The sample size was calculated by performing a pilot study based on the MetS variables, which encompassed the main morbidities that are risk factors for CVD. An initial estimated prevalence of $21.1 \%$ was determined. The sample size calculation was based on this estimate, for a 95\% confidence interval and $6 \%$ error (higher or lower), yielding a total sample of 178 nurses to be interviewed.

The data collected by the questionnaire were entered into an $\mathrm{Excel}^{\circledR}$ spreadsheet designed for this purpose. The following variables were summarized using the pertinent descriptive measures: mean, standard deviation, median, quartiles, and minimum and maximum values for the quantitative variables, whereas results were expressed as absolute (n) and relative (\%) frequencies for categorical variables.

\section{RESULTS}

\section{Sociodemographic data}

The age of patients ranged from 46 to 65 years, with mean age of $53.9 \pm 5.1$ years, and $49(22.5 \%)$ individuals were between 46 and 49 years of age, 129 (59.2\%) between 50 and 59 years, and $40(18.3 \%)$ were between the ages of 60 and 65 years.

\section{Lifestyle habits}

Of note, $18(8.3 \%)$ participants were smokers and 33 (15.2\%) former smokers; 83 (38.2\%) were alcohol users and 134 (61.8\%) were non-users; $99(45.6 \%)$ engaged in regular physical activity and 118 (54.4\%) performed no regular physical exercise.

\section{Anthropometric data}

Nurses had a mean height of $1.60 \mathrm{~m}$, ranging from 1.37 to $1.80 \mathrm{~m}$. Bodyweight ranged from 43 to $127 \mathrm{~kg}$, with a mean 
of $71.3 \mathrm{~kg}( \pm 13.6)$; waist circumference range was $58-167 \mathrm{~cm}$, with a mean of $91.6 \mathrm{~cm}( \pm 14.5)$; body mass index (BMI) was in the range of $16.7-43.9 \mathrm{~kg} / \mathrm{m}^{2}$, with a mean of $27.8 \mathrm{~kg} / \mathrm{m}^{2}$ $( \pm 4.9)$, where 60 (27.9\%) had $\mathrm{BMI}<25 \mathrm{~kg} / \mathrm{m}^{2}, 97(45.1 \%)$ had $25-29.9 \mathrm{~kg} / \mathrm{m}^{2}$, and $58(27.0 \%)$ had $\geq 30 \mathrm{~kg} / \mathrm{m}^{2}$.

\section{Menstrual pattern}

A total of $153(70.5 \%)$ respondents no longer menstruated, while $64(29.5 \%)$ still menstruated. Of the group still menstruating, 35 (54.7\%) had a regular cycle, 28 (43.7\%) had an irregular cycle, and $1 \mathrm{did}$ not answer this question. Of the group not menstruating, 34 (22.2\%) ceased menstruating after surgery, 68 (44.5\%) naturally, and the remaining 51 (33.3\%) reported no information for this variable. Age at last menstruation ranged from 19 to 57 years, with a mean of 47.5 years $( \pm 6.2)$. Time in menopause ranged from 1 to 26 years, where half of the nurses reported $<6$ years since menopause and the other half $\geq 6$ years.

\section{Menopausal symptoms}

The presence and intensity of the symptoms related to the climacteric were determined using the MRS (Table 1).

Each symptom is rated on a 5-point Likert-type scale of rising intensity values, where $0=$ no and little, $1=$ mild,
$2=$ moderate, $3=$ severe, and $4=$ very severe. Total score ranges from 0 to 44, where scores on the somatic and psychological symptom domains range from 0 to 16 points and on the urogenital domain 0 to 12 points. Higher scores indicate greater symptom intensity ${ }^{11-13}$.

Among nurses who reported at least one of the symptoms for the respective domains, results were as follows:

- Somatic: 140 (65.1\%) had joint and muscle complaints; 122 (56.7\%) hot flushes or sweating; $113(52.6 \%)$ sleeping disorders; 69 (32.1\%) cardiac complaints.

- Psychological: 156 (72.6\%) physical and mental exhaustion; 120 (55.8\%) irritability; 106 (49.3\%) anxious; $102(47.4 \%)$ depressed;

- Urogenital: 128 (59.5\%) sexual problems; 73 (34.0\%) urinary complaints; 115 (53.5\%) vaginal dryness.

Domain and total scores were tallied for the 196 study participants who provided answers for all symptoms on the scale (Table 2).

\section{Morbidities and medications used}

The nurses answered questions based on the presence of morbidities and the use of medications for their treatment (Table 3).

Table 1. Intensity of climacteric-related symptoms, as measured on the Menopause Rating Scale (MRS), for participants reporting at least one symptom ( $n=215)$, age 46-65 years, January 2018 to July 2019.

\begin{tabular}{|c|c|c|c|c|}
\hline Symp & & & & \\
\hline & $\mathrm{n}$ & $\%$ & $n$ & 0 \\
\hline
\end{tabular}

Somatic

\begin{tabular}{|c|c|c|c|c|c|c|c|c|c|c|c|c|}
\hline Hot flushes & 91 & 42.3 & 61 & 28.4 & 33 & 15.3 & 20 & 9.3 & 8 & 3.7 & 2 & 0.9 \\
\hline Heart discomfort & 145 & 67.4 & 44 & 20.5 & 21 & 9.8 & 3 & 1.4 & 1 & 0.5 & 1 & 0.5 \\
\hline Sleep problems & 100 & 46.5 & 28 & 13.0 & 49 & 22.8 & 27 & 12.6 & 9 & 4.2 & 2 & 0.9 \\
\hline Joint and muscle discomfort & 73 & 34.0 & 52 & 24.2 & 42 & 19.5 & 33 & 15.3 & 13 & 6.0 & 2 & 0.9 \\
\hline \multicolumn{13}{|l|}{ Psychological } \\
\hline Depressive mood & 111 & 51.6 & 51 & 23.7 & 35 & 16.3 & 14 & 6.5 & 2 & 0.9 & 2 & 0.9 \\
\hline Irritability & 90 & 41.9 & 55 & 25.6 & 43 & 20.0 & 18 & 8.4 & 4 & 1.9 & 5 & 2.3 \\
\hline Anxiety & 105 & 48.8 & 45 & 20.9 & 36 & 16.7 & 17 & 7.9 & 8 & 3.7 & 4 & 1.9 \\
\hline Physical and mental exhaustion & 58 & 27.0 & 73 & 34.0 & 42 & 19.5 & 36 & 16.7 & 5 & 2.3 & 1 & 0.5 \\
\hline \multicolumn{13}{|l|}{ Urogenital } \\
\hline Sexual problems & 86 & 40.0 & 45 & 20.9 & 47 & 21.9 & 27 & 12.6 & 9 & 4.2 & 1 & 0.5 \\
\hline Bladder problems & 142 & 66.0 & 42 & 19.5 & 23 & 10.7 & 7 & 3.3 & 1 & 0.5 & 0 & 0.0 \\
\hline Vaginal dryness & 97 & 45.1 & 41 & 19.1 & 41 & 19.1 & 27 & 12.6 & 6 & 2.8 & 3 & 1.4 \\
\hline
\end{tabular}

n: absolute number of responses per item. 
Table 2. Climacteric symptom scores, as measured on the Menopause Rating Scale (MRS), for participants answering all items of respective domains ( $n=196)$, age 46-65 years, January 2018 to July 2019.

\begin{tabular}{l|c|c|c|c}
\multirow{2}{*}{ Scores } & \multicolumn{4}{|c}{ Domains and symptoms } \\
\cline { 2 - 5 } Mean (SD) & Somatic & Psychological & Urogenital & Total \\
\hline Median (Q1; Q3) & $4.0(3.2)$ & $4.1(3.7)$ & $2.7(2.6)$ & $10.8(8.1)$ \\
\hline Minimum; maximum & $4.0(1.0 ; 6.0)$ & $3.0(1.0 ; 6.0)$ & $2.0(0.0 ; 4.0)$ & $9.0(5.0 ; 16.5)$ \\
\hline
\end{tabular}

SD: standard deviation; Q1: first quartile; Q3: third quartile.

Table 3. Morbidities present and medications used by participant nurses, age 46 to 65, January 2018 to July 2019.

\begin{tabular}{l|l|c|c|c|c}
\multicolumn{2}{c}{ Morbidities } & \multicolumn{2}{c}{ Morbidities present } & \multicolumn{2}{c}{ Medications used } \\
\hline Total responses & & $n$ & $\%$ & $n$ & $\%$ \\
\hline Anxiety & $214^{*}$ & 88 & 41.1 & 19 & 8.9 \\
\hline Syslipidemia & $214^{*}$ & 76 & 35.5 & 44 & 20.6 \\
\hline Depremic arterial hypertension & $216^{*}$ & 67 & 31.0 & 62 & 28.7 \\
\hline Rheumatologic diseases & $209^{*}$ & 41 & 19.6 & 20 & 9.6 \\
\hline Osteoporosis & $216^{*}$ & 32 & 14.8 & 12 & 5.6 \\
\hline Coronary heart disease & $213^{*}$ & 24 & 11.3 & 16 & 7.5 \\
\hline Diabetes mellitus & $214^{*}$ & 22 & 10.3 & 7 & 3.3 \\
\hline Malignant tumor & $215^{*}$ & 22 & 10.2 & 22 & 10.2 \\
\hline Deep vein thrombosis & $217^{*}$ & 12 & 5.5 & 7 & 3.2 \\
\hline Stroke & $217^{*}$ & 7 & 3.2 & 2 & 0.9 \\
\hline Pulmonary embolism & $217^{*}$ & 6 & 2.8 & 2 & 0.9 \\
\hline
\end{tabular}

*Total de respostas por item; n: número absoluto de respostas por item; \%: porcentagem.

\section{DISCUSSION}

This is the first cross-sectional descriptive study of nurses from São Paulo, Brazil, practicing in the climacteric period at public and private health institutions, exploring the morbidities and medications used by this group of professionals.

Nursing in Brazil is the largest category in the health field employing the highest number of women'. Thus, this study group was selected based on the predominance of women in the nursing team, participant experience in the health area, and the ability to furnish information on health changes. Moreover, to ensure a homogeneous sample, only individuals holding nursing degrees were selected.

In the State of São Paulo, $46.0 \%$ of women are in the climacteric period, indicating that the remaining $53.2 \%$ will go on to experience this phase, where $0.8 \%$ have already gone through this stage?.

In this study, $72.1 \%$ of participants had a BMI $>25 \mathrm{~kg} / \mathrm{m}^{2}$ and thus classified as overweight or obese. This rate proved higher than that for the Brazilian general population. We believed that these long working hours, operational demands, and non-observance of mealtimes are additional risk factors for obesity in the study group ${ }^{14-16}$.

The results revealed that the proportion of non-smokers was greater than current and former smokers. Similarly, more nurses were non-drinkers than drinkers. For physical activity, over half of the sample did not engage in regular exercise. Studies show that regular exercise reduces the risk of CVDs and osteoporosis, besides promoting esthetic and mood benefits ${ }^{17}$.

The mean age at last menstruation was 47.5 years $( \pm 6.2)$. This value is low compared with the first population-based study of Brazilian women conducted in 2003, which found a mean age at natural menopause of 51.2 years $^{18}$. In contrast, a more recent study of 749 women in the Southeastern region of Brazil found a mean age of $46.5( \pm 8.5)$, a result similar to that of this study $^{19}$. In a health study involving Chinese nurses, the results were again similar, identifying a mean age at natural menopause 
of 48.6 years $( \pm 3.61)^{20}$. Data published by the World Health Organization state that the most common age range for natural menopause is between 45 and 55 years, where this study result lies within this expected age range $e^{4}$.

Regarding the symptoms assessed by the MRS, the total score corresponds to a moderate symptom rating. These study results are in line with those reported by an investigation of Chinese nurses and women in general, conducted in the Southeast of Brazil, reporting a mean score of $9.8( \pm 7.9)$. However, these scores vary depending on the country, culture, and socioeconomic and educational background of the population studied. Understanding and controlling these factors can help reduce climacteric symptoms and target those groups most needing assistance $^{13,19,20}$.

Psychological and somatic symptoms proved more severe and frequent than urogenital symptoms, most notably physical and mental exhaustion. Also, hot flushes, irritability, anxiety, and depression were reported by around $50 \%$ of the nurses, relevant results that may impact the performance of work activities by these professionals.

In the study of Japanese nurses, the authors concluded that health professionals should be aware that menopausal symptoms are associated with job-related stress factors ${ }^{21}$.

In the United Kingdom, 45\% are registered experiencing the host of symptoms that menopause can cause $\mathrm{e}^{22}$.

Besides the specific symptoms of the climacteric in this study, $75.7 \%$ of participants reported more than one morbidity, including, in decreasing order of incidence: dyslipidemia, systemic arterial hypertension, arthrosis, arthritis or rheumatological diseases, coronary heart disease, diabetes mellitus (DM), malignant tumors, and risk factors for CVD.

In fact, data from the Ministry of Health show that CVDs account for 3 of the 10 most common causes of death in the female population in Brazil ${ }^{2}$. A study based on the presence of multimorbidity and associated factors in Brazilian women found that sedentarism, obesity, irritability, and postmenopause were associated with multimorbidity 5 .

Preventing CVD in postmenopausal women is critical, given the incidence of this disease rises with age. The condition is of multifactorial origin and can be influenced by modifiable risk factors such as smoking, sedentarism, poor diet, and elements of Met $\mathrm{S}^{2-5}$.
With regard to the use of medications for treating the morbidities reported by the nurses, good adherence in the study group was noted for diseases requiring strict medication control, such as subarachnoid hemorrhage and DM. All of those nurses who reported having diabetes and $92.5 \%$ of those with arterial hypertension were in use of medications for treatment, possibly due to their knowledge of the health area. However, rates for the other conditions were lower.

\section{CONCLUSIONS}

The most prevalent climacteric symptoms were somatic and psychological, most notably physical and mental exhaustion and muscle and joint issues. The most common morbidities were anxiety, dyslipidemia, arterial hypertension, depression, arthrosis, arthritis and rheumatologic diseases, osteoporosis, $D M$, and coronary heart disease. The most frequently used medications were antihypertensive agents, antidyslipidemic agents (statins), antidiabetic agents, antidepressants, and calcium supplements.

These results can help guide the development of health strategies aimed at health prevention among women in nursing. This group represents a large workforce with a key role in providing essential health services at all levels of health care, and such strategies can promote better working conditions, mechanisms for reducing occupational stress, as well as educational and preventive measures targeting the main risk factors for morbidities to which nurses are exposed in this period.

\section{ACKNOWLEDGMENT}

The authors thank the technical staff of the Faculdade de Ciências Médicas da Santa Casa de São Paulo - São Paulo (SP), Brazil.

\section{AUTHORS" CONTRIBUTIONS}

MCTB: Conceptualization, Data curation, Formal analysis, Funding acquisition, Investigation, Methodology, Project administration, Resources, Software, Visualization, Writing - original draft, Writing - review \& editing. SMRRL: Conceptualization, Data curation, Formal analysis, Funding acquisition, Methodology, Project administration, Resources, Software, Supervision, Validation, Visualization, Writing - review \& editing.

\section{REFERENCES}

1. World Health Organization. The world health report 1998: life in the 21st century. A vision for all. Geneva: World Health Organization; 1998 [cited on May 27, 2020]. Available from: https://www.who.int/whr/1998/en/whr98_en.pdf
2. Brasil. Ministério da Saúde. Protocolos da atenção básica: saúde das mulheres. Brasíli: Ministério da Saúde; 2016 [cited on Mar 7, 2017]. Available from: http://bvsms.saude.gov.br/bvs/ publicacoes/protocolos_atencao_basica_saude_mulheres.pdf 
3. Harlow SD, Gass M, Hall JE, Lobo R, Maki P, Rebar RW, et al. Executive summary of the stages of reproductive aging workshop + 10: addressing the unfinished agenda of staging reproductive aging. Menopause. 2012;19(4):387-95. http:// doi.org/10.1097/gme.0b013e31824d8f40

4. Valença CN, Germano RM. Concepções de mulheres sobre menopausa e climatério. Rev Rene. 2010;11(1):161-71. Available from: https://www.scielosp.org/article/sausoc/2010. v19n2/273-285/

5. Machado VSS, Valadares ALR, Costa-Paiva L, Morais SS, Pinto-Neto AM. Morbidades e fatores associados em mulheres climatéricas: estudo de base populacional em mulheres com 11 anos ou mais de escolaridade. Rev Bras Ginecol Obstet. 2012;34(5):215-20. https://doi.org/10.1590/S010072032012000500005

6. Lima SMRR, Botogoski SR, Reis BF. Conceitos. In: Lima SMRR, Botogoski SR, Reis BF, eds. Menopausa: o que você precisa saber. Abordagem prática e atual do período do climatério.

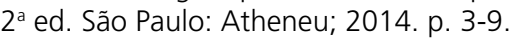

7. Sociedade Brasileira de Hipertensão, Sociedade Brasileira de Cardiologia, Sociedade Brasileira de Endocrinologia e Metabologia, Sociedade Brasileira de Diabetes, Sociedade Brasileira para Estudos da Obesidade. I diretriz brasileira de diagnóstico e tratamento da síndrome metabólica. Arq Bras Cardiol. 2005;84(Suppl 1):1-28.

8. Conselho Federal de Enfermagem. Decreto $n^{\circ} 94.406 / 87$, de 08 de junho de 1987. Regulamenta a Lei no 7.498, de 25 de junho de 1986, que dispõe sobre o exercício da Enfermagem e dá outras providências. Brasília: COFEN; 1987. Available from: http://www.cofen.gov.br/decreto-n-9440687_4173.html.

9. Conselho Federal de Enfermagem. Enfermagem em números. Quantitativo de profissionais de enfermagem por regional [Internet] 2020. Available from: http://www.cofen.gov.br/ enfermagem-em-numeros

10. Brasil. Ministério da Saúde. Conselho Nacional de Saúde. Resolução n 466, de 12 de dezembro de 2012. Dispõe sobre diretrizes e normas de pesquisas envolvendo seres humanos. Brasília: Ministério da Saúde; 2012. Available from: https://bvsms.saude.gov.br/bvs/saudelegis/cns/2013/ res0466_12_12_2012.html

11. Utian WH. The International Menopause Society menopauserelated terminology definitions. Climacteric. 1999;2(4):284-6. http:// doi.org/10.3109/13697139909038088

12. Heinemann K, Ruebig A, Potthoff P, Schneider HPG, Strelow $F$, Heinemann LAJ, et al. The Menopause Rating Scale (MRS) scale: a methodological review. Health Qual Life Outcomes. 2004;2:45. http://doi.org/10.1186/1477-7525-2-45
13. Lisboa LL, Utian W, Fonseca Filho GG, Azevedo GD. Tradução, adaptação e validação da versão brasileira do questionário Utian Quality of Life para avaliação da qualidade de vida no climatério. Rev Bras Ginecol Obstet. 2015;37(11):520-5. doi: https://doi.org/10.1590/S0100-720320150005438

14. Machado VSS, Valadares ALR, Costa-Paiva LH, Osis MJ, Sousa $\mathrm{MH}$, Pinto-Neto AM. Aging, obesity, and multimorbidity in women 50 years or older: a population-based study. Menopause. 2013;20(8):818-24. http://doi.org/10.1097/ GME.0b013e31827fdd8c

15. Gonçalves JTT, Silveira MF, Campos MCC, Costa LHR. Sobrepeso e obesidade e fatores associados ao climatério. Ciênc Saúde Colet. 2016;21(4):1145-55. https://doi.org/10.1590/141381232015214.16552015

16. Lee GJ, Kim K, Kim SY, Kim JH, Suh C, Son BC, et al. Effects of shift work on abdominal obesity among 20-39-year-old female nurses: a 5-year retrospective longitudinal study. Ann Occup Environ Med. 2016;28:69. http://doi.org/10.1186/ s40557-016-0148-6

17. Coelho CF, Burini RC. Atividade física para prevenção e tratamento das doenças crônicas não transmissíveis e da incapacidade funcional. Rev Nutr. 2009;22(6):937-46. https:// doi.org/10.1590/s1415-52732009000600015

18. Pedro AO, Pinto Neto AM, Paiva LHSC, Osis MJ, Hardy E. Idade de ocorrência da menopausa natural em mulheres brasileiras: resultados de um inquérito populacional domiciliar. Cad Saúde Pública. 2003;19(1):17-25. https://doi.org/10.1590/ S0102-311X2003000100003

19. Lui Filho JF, Baccaro LFC, Fernandes T, Conde DM, Costa-Paiva L, Pinto Neto AM. Epidemiologia da menopausa e dos sintomas climatéricos em mulheres de uma região metropolitana no sudeste do Brasil: inquérito populacional domiciliar. Rev Bras Ginecol Obstet. 2015;37(4):152-8. https://doi.org/10.1590/ SO100-720320150005282

20. Liu M, Wang Y, Li X, Liu P, Yao C, Ding Y, et al. A health survey of Beijing middle-aged registered nurses during menopause. Maturitas. 2013;74(1):84-8. http://doi.org/10.1016/j. maturitas.2012.10.006

21. Matsuzaki K, Uemura H, Yasui T. Associations of menopausal symptoms with job-related stress factors in nurses in Japan. Maturitas. 2014;79(1):77-85. http://doi.org/10.1016/j. maturitas.2014.06.007

22. Dean E. Menopause: why nurses need help from their employers. Nursing Standard [Internet] 2018 [cited on May 27, 2020]. Available from: https://rcni.com/nursingstandard/features/menopause-why-nurses-need-help-theiremployers-132511 